\title{
Temperature-dependence of a GaN-based HEMT monolithic X- band low noise amplifier
}

\author{
R.S. Schwindt', V. Kumar', O. Aktas ${ }^{3}$, J.-W. Lee ${ }^{4}$, I. Adesida ${ }^{2}$ \\ 'Dept. of Engineering, Union University, Jackson, TN, USA, rschwind@uu.edu \\ ${ }^{2}$ Micro and Nanotechnology Laboratory and Dept. of Electrical and Computer Engineering, \\ University of Illinois at Urbana-Champaign, Urbana, IL, USA \\ vkumar3@uiuc.edu, iadesida@uiuc.edu \\ ${ }^{3}$ Dept. of Electrical and Electronics Engineering, Bilkent University, Ankara, Turkey, oaktas@bilkent.edu.tr \\ ${ }^{4}$ School of Electronics and Information, Kyung Hee University, Suwon, Korea, jwlee@khu.ac.kr
}

\begin{abstract}
The temperature-dependent performance of a fully monolithic AlGaN/GaN HEMT-based X-band low noise amplifier is reported. The circuit demonstrated a noise figure of $3.5 d B$, gain of $7.5 d B$, input return loss of $-7.5 d B$, and output return loss of $-15 \mathrm{~dB}$ at $8.5 \mathrm{GHz}$ at room temperature. The noise figure at $9.5 \mathrm{GHz}$ increased from $2.5 \mathrm{~dB}$ at $43^{\circ} \mathrm{C}$ to $5.0 \mathrm{~dB}$ at $150^{\circ} \mathrm{C}$.
\end{abstract}

\section{Keywords}

$\mathrm{GaN}$, gallium nitride, SiC, wide bandgap, HEMT, low noise, amplifier, MMIC

\section{INTRODUCTION}

The outstanding properties of the Group III-nitride semiconductors (InN, GaN, AlN) such as chemical inertness, wide bandgap, high electron mobility, and high breakdown field have made possible heterostructure devices with high speed, low noise, and very high power performance suitable for harsh environment applications (see for example [3], [4], [7]). Most research in GaN-based transistors has focused on the high power performance of these devices, and as a result, the only AlGaN/GaN HEMT-based low noise amplifier (LNA) reported until very recently was a hybrid circuit [6]. Very recently a few monolithic LNAs have been reported which operated below X-band or which employed sub-quarter-micron gate-length devices or both [1], [2], [8]. This work reports on the temperaturedependent performance of a monolithic microwave integrated circuit (MMIC): an AlGaN/GaN high electron mobility transistor (HEMT)-based low noise amplifier operating at $\mathrm{X}$-band and employing a reliable $0.25-\mu \mathrm{m}$ gatelength technology. The results demonstrate the potential for the integration of a robust low noise amplifier with an ultrahigh performance power amplifier in a single technology for next-generation military and communication systems.

\section{DEVICE AND FABRICATION}

A photograph of the GaN-based MMIC LNA is shown in Figure 1. As indicated by Figure 1, the circuit is a singlestage design employing a single $2 \times 75 \mu \mathrm{m}$ GaN-based HEMT. The circuit was fabricated on an epilayer grown by

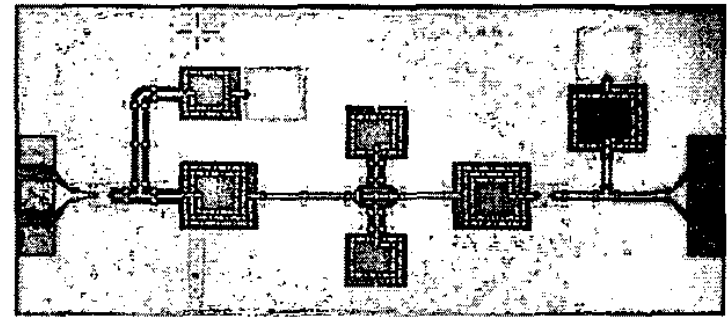

Figure 1. Photograph of the X-band GaN-based LNA MMIC.

MOCVD on a semi-insulating $4 \mathrm{H}-\mathrm{SiC}$ substrate. The epilayer consists of a buffer, $2-\mu \mathrm{m}$ undoped $\mathrm{GaN}$, a 3-nm undoped $\mathrm{Al}_{0.25} \mathrm{Ga}_{0.75} \mathrm{~N}$ spacer, a $10-\mathrm{nm}$ Si-doped $\left(\sim 1 \times 10^{19}\right.$ $\mathrm{cm}^{-3}$ ) $\mathrm{Al}_{0.25} \mathrm{Ga}_{0.75} \mathrm{~N}$ charge supply layer, and a $10-\mathrm{nm}$ undoped $\mathrm{Al}_{0.25} \mathrm{Ga}_{0.75} \mathrm{~N}$ barrier layer. The average sheet resistance of the sample was $453 \Omega /$ square. The first step for device fabrication was mesa-isolation using $\mathrm{Cl}_{2} / \mathrm{Ar}$ plasma in an inductively-coupled-plasma reactive ion etch (ICPRIE) system. Ohmic contacts were formed by rapid thermal annealing of evaporated $\mathrm{Ti} / \mathrm{Al} / \mathrm{Mo} / \mathrm{Au}$ at $850^{\circ} \mathrm{C}$ for $30 \mathrm{~s}$ [5]. The $0.25-\mu \mathrm{m}$ gate-length $\mathrm{T}$-shaped gates $(\mathrm{Ni} / \mathrm{Au})$ were defined using electron-beam lithography. The transistors had a source-drain spacing of $2.5 \mu \mathrm{m}$ and were passivated with $200 \mathrm{~nm}$ thick silicon nitride.

The integrated circuit fabrication process consisted of the following steps: mesa isolation, ohmic metal, Schottky gates via e-beam lithography, overlay metal, silicon nitride deposition and etch; nichrome resistor; a $1-\mu \mathrm{m}$-thick evaporated gold level; and airbridge. The process incorporates steps which allow the realization of the passive elements required for a complete coplanar waveguide-style MMIC process: low-loss transmission lines, metal-insulator-metal (MIM) capacitors, spiral inductors, and thin-film resistors. Because the LNA has relaxed requirements with respect to thermal impedance and source ground inductance compared to a high power amplifier, this initial LNA MMIC was designed using CPW-style transmission lines and passive elements so that backside processing was not required. 


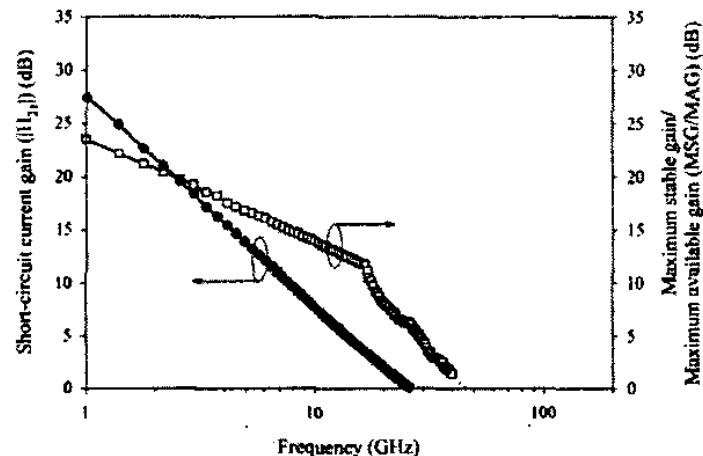

(a)

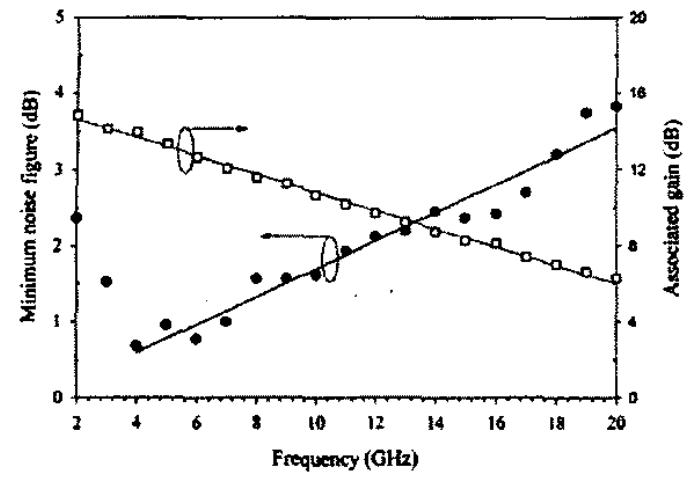

(b)

Figure 2. (a) Small signal performance of a typical 0.25$\mu \mathrm{m} \times 150-\mu \mathrm{m}$ HEMT at $25^{\circ} \mathrm{C}$. (b) Noise performance of a typical device at $25^{\circ} \mathrm{C}$.

\section{DEVICE CHARACTERISTICS}

A typical $0.25 \mu \mathrm{m} \times 150 \mu \mathrm{m}$ AIGaN/GaN HEMT has a maximum drain current density of $1.0 \mathrm{~A} / \mathrm{mm}$ and a peak DC extrinsic transconductance of $170 \mathrm{mS} / \mathrm{mm}$. The threshold voltage is $-6.8 \mathrm{~V}$, where the threshold voltage was determined by extrapolating the drain current to zero from the maximum transconductance point.

The small signal and noise performance of a typical $.25 \mu \mathrm{m}$ $\times 150 \mu \mathrm{m} \mathrm{AlGaN} / \mathrm{GaN}$ HEMT at $25^{\circ} \mathrm{C}$ are shown in Figure 2. Small signal characteristics were measured using an Agilent $8510 \mathrm{~B}$ network analyzer. Figure 2(a) shows the short-circuit current gain $\left(\left|\mathrm{H}_{21}\right|\right)$ and the maximum stable gain/maximum available gain (MSG/MAG) at the device's peak- $f_{T}$ bias point of $13 \mathrm{~V}$ drain-source voltage, $-6.0 \mathrm{~V}$ gate-source voltage and $34.6 \mathrm{~mA}$ drain current. The $f_{T}$ of the device is $24.5 \mathrm{GHz}$. The maximum frequency of oscillation $f_{\max }$ is $48 \mathrm{GHz}$ and is determined by extrapolating the maximum available gain (MAG) at $-20 \mathrm{~dB} /$ decade.

A Maury/ATN NP5 noise parameter measurement system along with an Agilent 8970B noise figure meter and 8971C noise figure test set was used to measure device noise parameters from 2 to $20 \mathrm{GHz}$. Figure 2(b) shows the device's

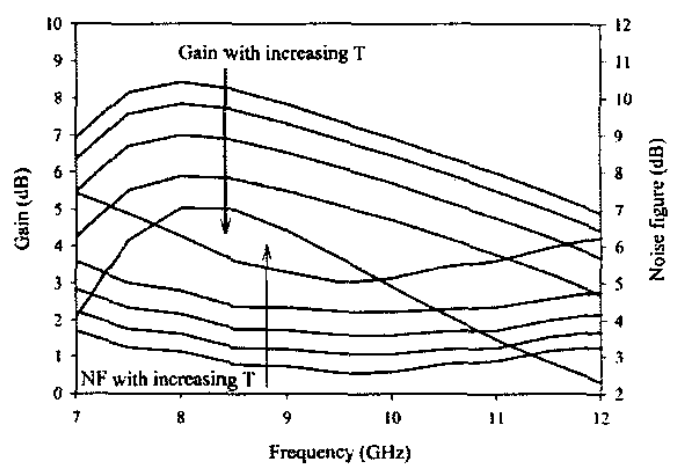

Figure 3. Gain and noise figure of the LNA MMIC at $43^{\circ} \mathrm{C}, 0^{\circ} \mathrm{C}, 50^{\circ} \mathrm{C}, 100^{\circ} \mathrm{C}$, and $150^{\circ} \mathrm{C}$. Bias is $V_{\mathrm{os}}=$ $8 \mathrm{~V}, \mathrm{I}_{0}=40 \mathrm{~mA}$.

minimum noise figure and associated gain at $25^{\circ} \mathrm{C}$ at the device's minimum noise figure bias of $10 \mathrm{~V}$ drain-source voltage, $-6.7 \mathrm{~V}$ gate-source voltage and $10 \mathrm{~mA}$ drain current. The minimum noise figure at $10 \mathrm{GHz}$ is seen to be 1.6 $\mathrm{dB}$ with an associated gain of $10.6 \mathrm{~dB}$.

\section{CIRCUIT PERFORMANCE}

The single-stage LNA employs spiral inductors between the HEMT's source and ground to provide series inductive feedback to bring the optimum noise match $\Gamma_{\text {opt }}$ closer to $S_{11}{ }^{*}$ to achieve acceptable input return loss while at the same time matching for the optimum noise performance. The output matching network was designed for optimum small signal gain. Bias is applied through the RF input and output probe pads, and bypass capacitors provide $\mathrm{AC}$ grounds for the shunt inductors in the input and output matching networks.

Figure 3 shows the small signal and noise performance of the LNA from $-43^{\circ} \mathrm{C}$ to $+200^{\circ} \mathrm{C}$. At $-43^{\circ} \mathrm{C}$, the noise figure reached a minimum of $2.5 \mathrm{~dB}$ at $9.5 \mathrm{GHz}$, and at 150 ${ }^{\circ} \mathrm{C}$ the noise figure at $9.5 \mathrm{GHz}$ was $5.0 \mathrm{~dB}$. At $25^{\circ} \mathrm{C}$ the monolithic microwave integrated circuit (MMIC) demonstrated a noise figure of $3.5 \mathrm{~dB}$, gain of $7.5 \mathrm{~dB}$, input return loss of $-7.5 \mathrm{~dB}$, and output return loss of $-15 \mathrm{~dB}$ at 8.5 $\mathrm{GHz}$. The rate of change in gain and noise figure with temperature is fairly constant across the frequency band up to $100{ }^{\circ} \mathrm{C}$ while at $150^{\circ} \mathrm{C}$ the gain and noise figure are degraded non-uniformly across frequency. While encouraging, this suggests that the excellent high temperature $(\sim 500$ ${ }^{\circ} \mathrm{C}$ ) operation expected from $\mathrm{GaN}$-based technology has not been fully realized.

\section{CONCLUSION}

The temperature-dependent performance of a fully monolithic $\mathrm{AlGaN} / \mathrm{GaN}$-based LNA has been presented. Combined with the very high microwave power performance previously demonstrated by AlGaN/GaN-based HEMTs, these results demonstrate the potential for the integration of a robust low noise amplifier with an ultra-high performance 
power amplifier in a single GaN-based technology for nextgeneration military and communication systems.

\section{ACKNOWLEDGMENTS}

This work was supported by ONR under contract No. N00014-01-1-1000 (monitor: Dr. H. Dietrich) and contract No. N0014-1-1072 (monitor: Dr. H. Dietrich).

\section{REFERENCES}

[1] S. Cha, Y. H. Chung, M. Wojtowicz, I. Smorchkova, B. R. Allen, J. M. Yang, and R. Kagiwada, 2004 IEEE International Microwave Symp. Dig., pp. 829-832.

[2] G. A. Ellis, J.-S. Moon, D. Wong, M. Micovic, A. Kurdoghlian, P. Hashimoto, and M. Hu, 2004 IEEE International Microwave Symp. Dig., pp. 153-156.

[3] W. Lu, V. Kumar, R. Schwindt, E. Piner, and I. Adesida, Solid State Electronics, vol. 46, pp. 1441-1444, 2002.
[4] N. X. Nguyen, M. Micovic, W.-S. Wong, P. Hashimoto, P. Janke, D. Harvey, and C. Nguyen, Electron. Lett., vol. 36, pp. 469-471, 2000.

[5] D. Selvanathan, L. Zhou, V. Kumar, and I. Adesida, phys. stat. sol. (a) vol. 194, pp. 583-586, 2002.

[6] R. Welch, T. Jenkins, B. Neidhard, L. Kehias, T. Quach, P. Watson, R. Worley, M. Barskey, R. Sandhu, and M. Wojtowicz, 2001 IEEE GaAs IC Symp. Dig., pp. 153-155.

[7] Y.-F. Wu, A. Saxler, M. Moore, R.P. Smith, S. Sheppard, P.M. Chavarkar, T. Wisleder, and U.K. Mishra, IEEE Electron Device Lett., vol. 25, pp. 117 119, 2004.

[8] H. Xu, C. Sanabria, A. Chini, S. Keller, U. K. Mishra, and R. A. York, IEEE Microwave and Wireless Components Lett., vol. 14, pp. 262-264, 2004. 
. 